\title{
Life be in it: Lifestyle choices for active leisure
}

\author{
Anne Jobling \\ Schonell Special Education Research Centre, University of Queensland, Australia \\ This paper was presented at the 6th World Congress on Down Syndrome \\ in Madrid, Spain, October 1997
}

\begin{abstract}
For members of the community, participation in leisure, sports and recreation is an important lifestyle choice. Individuals with Down syndrome live in our community and they, too, are equally entitled to active lifestyle choices. Children, adolescents and adults with Down syndrome have a wide range of interests and, although reported trends indicate that their engagement in recreational activity is often sedentary and solitary in nature, other factors apart from the syndrome may account for this. Using a perception of difference perspective, this paper will examine certain aspects of their motor development, health and interactions with others which could be viewed as restrictive factors to their ability to participate in active leisure opportunities in the community. Program examples from Australia will be used to illustrate how a perception of difference which facilitates ability rather than disability across community based activities can enable a range of active leisure choices.
\end{abstract}

Keywords — Down syndrome, leisure, sports, physical activity, Australia

\section{Introduction}

Although it is recognized that there are many valuable passive leisure and recreational activities, this paper will particularly examine the physically active aspects of leisure, sports and recreation within the lives of individuals with Down syndrome. A 'perception of differences' concept (Evans, 1993) will be used to highlight the importance of attitudes and values in the development of programs, and some Australian programs will be discussed. Physically active recreation presents many benefits for us all. Some benefits are health related (Corbin \& Lindsey, 1984); some are associated with peers and friends (Moon, 1994) while others have to do with an individual's own feelings of independence and self-worth (Reid \& Hermo, 1998). This is also the case for individuals with Down syndrome (Reid \& Block, 1996; Jobling \& Hayes, 1991) although little research has been done specifically to assess these aspects for individuals with Down syndrome.

Australians are considered to be physically active people; a land surrounded by water and inundated with athletes (Wind, 1960). They perceive themselves as a nation dedicated to sports and the adoration of sportspersons, and government campaigns through the Australian Sports Commission have continued to foster this with nationally funded programs. Some of these programs are related to elite sport such as the Olympic or Paralympic Games but others are aimed at encouraging families and individuals to select leisure pursuits (sports and recreation) in the outdoors and become active. In the 1980s, a national 'Life Be In It' program was used to raise awareness of familytype activities away from conventional sports, while more recently, 'Active Australia' is trying to get all Australians up, out of their TV chairs, and actively onto playing fields or into the park. Within the Australian community, both these campaigns recognize that being active assists the development of health related outcomes and promotes the making of social contacts and friendships for participants. These aspects of participation add to the individual's quality of life, and presently it has been stated that up to $70 \%$ of Australians are considered to regularly participate in physical activity (Kirk, 1996).

However, it has taken governments and the community some time to recognize that participation such as advocated by these campaigns should equally be available for people with disabilities. Previously, active recreation for people with disabilities was primarily viewed within a rehabilitative framework or as a way of filling free time, and a medical/therapeutic orientation to programs was often the focus (Schleien \& Ray, 1988). Terminology reflected this position with aspects of active recreation labeled 'therapeutic recreation' or 'dance therapy.' This focus is gradually changing with human experience rather than remediation being the focus. Physical well-being and active recreation 
and leisure interests are now seen as fundamental to a person's quality of life and they are given high priority in quality of life models for persons with disabilities (Brown, 1997). Quality of life models provide frameworks which are intended to assist in enhancing the life options of people with disabilities. However, the considerations and choices given to individuals with disabilities are often dependent on how the policy makers and the community views these individuals, and those views are often expressed in terms of differences.

\section{Perceptions of Difference}

Difference can be perceived in several ways. Differences are often represented by a set of characteristics, for example, short limbs, poor coordination, or a range of health problems. This 'characteristic' perception of differences often leads to programs that are narrow and restrictive, with time frames based on developmental outcomes which are considered appropriate for a child with the cited characteristics. Or alternatively, an intensive program is designed to specifically overcome their set of problems. Or these problems are seen as perceived barriers to participation making it too difficult and time consuming to initiate long-term options. These orientations, it is contended, lead to negative and 'fix-up' attitudes in programming. Attitudes and views with these orientations often result in low expectation, and low expectations can create a negative 'feedback cycle' for people with disabilities in the delivery of services, and thus reduce their quality of life options. Alternatively, however, differences can be seen as challenging, as a resource; differences can offer possibilities for creative change and the development of opportunities with long term value for the individuals. It is suggested that when one has this perception of difference shaping attitudes very different programs are developed - programs with high and positive expectations and lifespan options.

\section{How are perceptions of difference related to individuals with Down syndrome?}

Children and adults with Down syndrome are considered to differ from the general population, especially in developmental terms, and myths about these differences have been developed (Hayes \& Gunn, 1991). Many of these myths are associated with deficits in their abilities and lead to low expectations. Therefore, it is considered pertinent to consider the ways in which individuals with Down syndrome are perceived as different, and the effect these perceived differences may have on their opportunities in leisure, sports and recreation across their lifespan. For as Evans (1993) has stated, equity in life's choices is not just about giving every child an equal chance, it is about giving each child the best possible chance to develop and make the most of his/her own special talents.

\section{Difference as characteristics}

There are certainly a constellation of characteristics that can be associated with the syndrome, but as reported by Gunn (1993) none of these features actually defines Down syndrome and opinion is divided as to how many ought to be included to define the condition. All individuals with Down syndrome have extra chromosomal material, but they are not identical even with respect to this extra genetic material. In activity situations, individuals with Down syndrome have often been portrayed as being incompetent, inactive and having sedentary lifestyles. Their low level of motor skill, weight problems and the passive and unresponsive nature of their interactions in some situations are often considered responsible for this portrayal.

\section{Motor skill}

In many cases it is accurate to say that the development of motor skills in individuals with Down syndrome is slow and continually lags behind that of their peers. Various syndrome specific charateristics as well as aspects of their motor learning have been identified to explain this slow and low performance (Henderson, 1985; Reid \& Block, 1996). However, there is wide variability in performances and some children attain some motor skills that are equivalent to their chronological age (Jobling, 1999). Nevertheless, throughout infancy and into childhood, when compared to children without Down syndrome, individuals with Down syndrome develop a lower level of skill in some aspects of their motor performance (Reid \& Block, 1996; Dyer, 1994; Henderson, 1985; Jobling \& Gunn, 1995; Jobling, 1997). However, a resigned acceptance of this situation is untenable, for it may be that instruction which more specifically directs the child's attention to particular aspects of their performance and helps them to develop learning strategies could assist their understanding of ways in which they can improve their performance. In a study of balance Jobling (1997) observed that many children failed a series of balance tasks because they did not know how to stabilize their actions or used inappropriate strategies to correct their failing performances.

Educationally, for children with Down syndrome, motor skill development requires education in, through and about movements (Jobling, 1994) and the development of a 'movement language' to assist their understanding is essential. Knowledge about movement itself (Foster, 1976), how each movement can make up a skill and how a series of skills make up activity sequences are necessary components of this 'language.' Practice, too, is important as improved muscle tone, fitness and skill proficiency enhance opportunities to participate. However, practice sessions which rely on repetitive rote learning of skills need to be replaced with sessions that are fun and varied to maintain interest and provide information for further understanding. Children and adults with Down syndrome need an opportunity to gain an understanding of the game or activity; a knowledge of the environment, and the rules and strategies, as well as the social conventions. Burns and Gunn (1993) provide an 
excellent lifespan perspective for this type of approach to motor skill development.

\section{Obesity}

Some writers have suggested that the weight problems of individuals with Down syndrome limit their participation in active recreation and sports (Heyne, Schleien \& Rynders, 1998; Reid \& Block, 1996) and retard the development of motor skills which produces a lifestyle cycle of sedentary choices and increased weight gain. While there is considerable evidence to suggest a high level of sedentary activities and weight gains as children move into to adolescence (Buckley \& Sacks, 1987; Pueschel \& Sustrova, 1997), a ten year study of the motor development in school-aged children with Down syndrome found no significant relationship between the development of motor skill proficiency and obesity at age 16 (Jobling, 1999). This study considered that the interactional relationship may be more complex. As motor skills develop, it may be important to monitor the interaction between the level of motor skill proficiency attained and the age at which the child's weight starts to move into the obese classification. It could be that if motor proficiency is limited when weight is creeping towards an obese classification, this has a negative effect on further motor skill development, but the picture is unclear. However, obesity can clearly be responsible for the establishment of a negative activity participation cycle, so there is a need for more longitudinal examinations to ascertain the impact of "creeping obesity" on the progress of skill development and general quality of life. It must be remembered that children with Down syndrome are not the only group requiring investigation. Obesity is considered a chronic disease in one third of the US adult population (Rippe et al., 1998) and over $40 \%$ of Australians have a weight problem (National Heart Foundation, 1998).

\section{Inactivity}

When playing in active learning environments, young children with Down syndrome have been characterisised as unresponsive (Mundy et al., 1988; Beeghly et al., 1990). In the fast-paced environment of the preschool, Titus and Watkinson (1987) have suggested that this lack of response and play interactions may be due to a lack of skills. Several studies have demonstrated this (Hogg \& Moss, 1983; Malone \& Stoneman 1990; Jobling \& Gunn, 1995; Watkinson \& Mulion, 1988) and in special education settings it has been felt that children's play has often been controlled and orchestrated to meet intervention goals (Schwartzman, 1991; Shevin, 1987). Thus it may be that, lacking skills and the knowledge about activity situations and interactions, children with Down syndrome decide it is better to be inactive and just watch. Or is it that others (teachers or parents) are often responding for them (Fischer 1988; Stevenson et al., 1985) so, they just wait to see what happens! Unresponsiveness may be a learnt strategy as the result of experience rather than an inherent characteristic of the syndrome (Jobling, 1996). As Wishart (1995) suggests it is all too easy to conclude that behaviours are a consequence of the syndrome. In Australia it is worth noting that research has shown that 30 to $40 \%$ of Australian children are inactive - they "don't actively play anything” (Physical and Sport Education, 1992).

\section{How do programs reflect these differences in their planning?}

It could be suggested that recreation and sports participation programs of young adults with Down syndrome have been shaped to accommodate these characteristics (low skills, obesity and low activity levels). Myths of uniformity are perpetuated and syndrome-specific needs are seen as problems or barriers to overcome or are used to explain their low level of participation in activities. Where this has occurred, special programs have been designed to meet these perceived needs. 'Special' sports and 'handicapped only' recreation programs have narrow and restricted frameworks for participation (Schelein \& Ray, 1988) and are often promoted and organized on the basis of differences related to characteristics. Modifications and adaptations of skills and games are often done on the basis of generalized perceptions of motor skills, cognitive abilities and behaviours, and these are frequently associated with low expectations or 'can't dos' rather than on 'let's see what they can dos'!

Differences seen as problems or barriers have meant that short term goals rather than long term participation has frequently been the objective. Choices are often restricted due to generalizations about the participants especially those with Down syndrome. Knowledge about the wide range of individual difference in performances by those with the syndrome (Gunn \& Berry, 1986; Jobling \& Gunn, 1995) are ignored, or in some cases knowledge used for programming is out of date. There is a need for programmers to become more aware of the individual differences inherent in the syndrome. To become less accepting of characteristic-type orientations as they usually limit both the access and availability of active leisure for individuals with Down syndrome.

Alternatively, if differences are perceived as a challenge to develop opportunity, as source of possiblities and as a resource for creative changes in programs, then much can happen in active leisure for those with Down syndrome. Opportunities can be developed that enhance skills and make available knowledge for sport and recreation participation (Moon, 1994). Only by providing these opportunities can the narrow foci in programs and the limitations often imposed by characteristics be removed. This will require not only changes in the content of programs, but in the time frames given within programs to acquire skills and knowledge. It will require creative and innovative thinking about the way in which motor, health, fitness and social skills are taught to children and adults with Down syndrome. Everyone with Down syndrome is entitled to the best possible chance to develop and make the most of their own special talents - motorically and socially. Everyone with Down syndrome should have an opportunity to be fit and understand about their own health and fitness. The 
development of fitness requires motor skills, and knowledge of the possible fitness related benefits of activities. Children and adults can also learn about the influence of diet with exercise in weight control. Health problems such as obesity and heart abnormalities often associated with Down syndrome should be seen as a challenge rather than as a barrier or problem. Alternatives can be developed. Children and adults can learn about their own health problems, and develop an understanding of the impact that these problems have on their own active participation.

\section{Australian examples}

Two programs developed in Australia have taken up these challenges of difference: Coaching Athletes with Disabilities (1994) and Willing and Able (Downs, 1995). These programs have been designed for teachers and coaches to assist players such as those with Down syndrome to develop and have opportunities to learn and understand the activity skills. These programs not only provide opportunities for skill development, but also offer choice. The choices are related firstly, to the community environment in which the activity takes place and secondly, are aimed at enabling choice to be lifelong. Willing and Able (Downs, 1995) is a resource for teachers which was developed in conjunction with the Aussie Sports and Aussie Able programs which provide teachers with information, planning tools and the support necessary to plan and conduct activity programs that include young people with varying abilities. The principles behind the program espouse the value of physical activity for all. The Willing and Able program attempts to demonstrate to teachers that they can become more creative within their physical education curricula and move beyond the 'lock step' styles of curricula which are based on generalized normative patterns of development, and specific disability deficit characteristics. The materials assist teachers to examine the interactional patterns between the individual and the activity, and then apply the strategies needed to enable the participant to play.

In conjunction with this program a community-based sports coaching scheme has been developed. Coaching Athletes with Disabilities (CAD) (1994) has several components, one of which supports active participants with intellectual disability. It was initiated through the Australian Coaching Council which regulates coaching standards for all sports in Australia. This coaching scheme for athletes with disabilities aims to provide a set of guidelines for coaches of athletes/players with intellectual disability. The CAD program enables coaches to learn about working with difference in order to assist in the development of skills and knowledge in their various sports and activities. The program provides coaching clinics and workshops and assists with competitive structures and elite coaching. Materials, manuals and courses for coaches in sporting groups have been provided throughout Australia and overseas. Initially, the program relied heavily on special groups representing those with intellectual disability, such as Special Olympics and AUSRAPID, but now many of Australia's sports nationwide have adopted the principles and practices from these courses into their own coaching materials and courses. The role of 'special' groups related to a particular disability category is changing as more mainstream groups become involved.

One sport and recreational activity to take up this challenge of difference is Tennis Australia. Tennis Australia now has a video, a manual and course components that can assist coaches who may have players with Down syndrome in any region of the country. Should a player excel or wish competitive structures those have been put in place within mainstream tennis. At the highest levels, tennis now includes players with intellectual disability in their major events. In February 1998, the inaugural Australian Open for players with intellectual disability was held at Melbourne Park and other state championships have also been held.

This trend is exciting. At the State and Territory level, too, creative changes are taking place. Queensland has over twenty State Sporting Organisations providing coaching and participation opportunites for players with intellectual disability such as Down syndrome. These are all at different levels of development. Lawn bowls, athletics, swimming, ten pin bowling, indoor soccer and cricket, basketball, karate and netball have all accepted the challenge of difference to become more creative in their programming.

Both Willing and Able and Coaching Athletes with Disabilities are helping to provide links between community and school for active recreation and sports at all levels of participation. Adventure style activities such as mountain biking, yachting, rock climbing and canoeing are also adding creative elements to their programs for all Australians. Hopefully, these links can assist participants with Down syndrome to choose lifelong involvement in activity as opportunities to gain skills and knowledge and to participate are emerging.

\section{Conclusion}

In this paper, with illustrations from Australia, it has been contended that when differences are viewed as opportunities and exciting challenges, mainstream sport and recreation can actively initiate community-based programs for children and adults with disabilities such as Down syndrome. Opportunities to be creative enable community groups to develop resources and be actively involved. Thus active leisure can move beyond myths developed from too much attention to sets of characteristics, and beyond narrow restricted program models designed on the basis of problems and barriers to more inclusive programming. Leisure, sports and recreation participation is for all individuals and those with Down syndrome can say, see and experience for themselves through their skills, knowledge and participation in community environments that active leisure is a part of their life and they can be in it. 


\section{Correspondence}

Anne Jobling, PhD, Co-director, Down Syndrome Research Program, Schonell Special Education Research Centre, The University of Queensland, Brisbane, Queensland, 4072, Australia - Telephone +61733656405 - Facsimile +617 33658553 •E-mail a.jobling@mailbox.uq.edu.au

\section{References}

Beeghly, M.,Weiss-Perry, B. \& Cicchetti, D. (1990). Beyond sensorimotor functioning: Early communication and play development of children with Down syndrome. In D. Cicchetti and M. Beeghly (Eds.) Children with Down Syndrome: A Developmental Perspective. New York : Cambridge University Press. pp. 329-368.

Brown, R. (Ed.) (1997). Quality of Life for People with Disabilities. London: Chapman and Hall.

Buckley, S. \& Sacks, B. (1987). The Adolescent with Down Syndrome: Life for the Teenager and for the Family. Portsmouth, UK: Portsmouth Polytechnic.

Burns, Y. \& Gunn, P. (Eds.) (1993). Down Syndrome: Moving through Life. London: Chapman and Hall.

Coaching Athletes with Disabilities. (1994). Canberra, Australia: Australian Sports Commission

Corbin, C. \& Lindsey, R. (1984). The Ultimate Fitness Book. New York: Leisure Press.

Downs, P. (1995). Willing and Able. Canberra, Australia: Australian Sports Commission.

Dyer, S. (1994). Physiological effects of a 13 week physical fitness program on Down syndrome subjects. Pediatric Exercise Science, 6, 88-100.

Evans, J. (Ed.) (1993). Equality, Education and Physical Education. London: Falmer Press.

Fischer, M.A. (1988). The relationship between child initiation and maternal responses in preschool-age children with Down syndrome. In K. Marfo (Ed.), Parent-Child Interaction and Developmental Disabilities. New York: Praeger. pp. 126-144.

Foster, R. (1976). Knowing in my Bones. London: Adam and Charles Black.

Gunn, P. (1993). Characteristic of Down syndrome. In Y. Burns and P. Gunn (Eds.), Down Syndrome: Moving through Life. London: Chapman and Hall. pp. 1-14.

Gunn, P. \& Berry, P. (1986). The temperament of Down syndrome children. In J. Berg (Ed.), Science and Service in Mental Retardation. London: Methuen. pp. 149-158.

Hayes, A. \& Gunn, P. (1991). Developmental assumptions about Down syndrome. In C. Denholm (Ed.), Adolescents with Down Syndrome: International Perspectives on Research and Programme Development. Victoria, BC: University of Victoria. pp. 73-82.

Henderson, S.E. (1985). Motor skill development. In D. Lane and B. Stratford (Eds.), Current Approaches to Down Syndrome. London: Cassell. pp. 187-218.

Heyne, L.A., Schleien, S.J. \& Rynders, J.E. (1998). Promoting quality of life through recreation participation. In S.M. Pueschel and M. Sustrova (Eds.), Adolescents with Down syndrome: Towards a More Fulfilling Life. Baltimore: Paul H. Brookes. pp. 317-340.
Hogg, J. \& Moss, S.C. (1983). Prehensile development in Down's syndrome and non-handicapped preschool children. British Journal of Developmental Psychology, 1, 189-204.

Jobling, A. (1994). Physical education for persons with Down syndrome: More than games. Down Syndrome Research and Practice, 2(1), 31-35.

Jobling, A. (1996). Play. In P. Gunn and B. Stratford (Eds.), New Approaches to Down Syndrome, pp.226-248. London: Cassell.

Jobling, A. (1997, May). Balance proficiency of children with Down syndrome. Paper presented at The $11^{\text {th }}$ International Symposium for Adapted Physical Activity, Quebec City, Canada.

Jobling, A. (1999). Attainment of motor proficiency in school aged children with Down syndrome. Adapted Physical Activity Quarterly, 16(4), 344-361.

Jobling, A. \& Gunn, P. (1995). The motor proficiency of children and adolescents with Down syndrome. In A. Vermeer and W. E. Davis (Eds.), Physical and Motor Development in Mental Retardation. Basel: Karger. pp. 181-190.

Jobling, A. \& Hayes, A. (1991). Integrating recreation into educational programmes for adolescents with Down syndrome. In C. Denholm (Ed.), Adolescents with Down Syndrome: International Perspectives on Research and Programme Development. Victoria, BC: University of Victoria. pp. 175-182.

Kirk, D. (1996). The crisis in school physical education: An argument against the tide. ACHPER Healthy Lifestyles, $43(4), 25-27$.

Malone, D. \& Stoneman, Z. (1990). Cognitive play of mentally retarded preschoolers: observations in the home and at school. American Journal of Mental Retardation, 94, 475-487.

Moon, M.S. (Ed.) (1994). Making School and Community Recreation Fun for Everyone. Baltimore: Paul H Brookes.

Mundy, P., Sigman, M., Kasari, C. \& Yirmiya, N. (1988). Nonverbal communication skills in Down's syndrome children. Child Development, 59, 235-249.

Physical and Sport Education: A Report by the Senate Standing Committee on Environment, Recreation and the Arts. (1992). Canberra: Australian Government Printer.

Pueschel, S.M. \& Sustrova, M. (1997). Adolescents with Down Syndrome: Towards a More Fulfilling Life. Baltimore: Paul H. Brookes.

Reid, G. \& Block, M. (1996). Motor development and physical education. In P. Gunn and B. Stratford (Eds.), New Approaches to Down Syndrome. London: Cassell. pp. 309-340.

Reid, G. \& Hermo, J. (1998) Beyond skill development. International Journal of Practical Approaches to Disability, 22(1), 17-21.

Rippe, J.M., Crossley, S. \& Ringer, R. (1998). Obesity as a chronic disease: Modern medical and lifestyle management. Journal of American Dietetic Association, 98, 9-15.

Schleien, S.J. \& Ray, M.T. (1988). Community Recreation and Persons with Disabilities: Strategies for Integration. Baltimore: Paul H Brookes.

Schwartzman, H. B. (1991). Imagining play. Play and Culture, 4, 214-22. 
Shevin, M. (1987). Play in special settings. In J. Block and N. King (Eds.), School Play: A Source Book. New York: Garland. pp. 219-251.

Stevenson, M B., Leavitt, L.A. \& Silverberg, S.B. (1985). Mother-infant interaction: Down syndrome case studies. In S. Harel and Anastasiow (Eds.), At Risk Infants: Psychological, Sociological and Medical Aspects. Baltimore: Paul H. Brookes. pp. 389-95.

Titus, J.A. \& Watkinson, E.J. (1987). Effects of segregated and integrated programs on the participation and social interaction of moderately mentally handicapped children in play. Adapted Physical Activity Quarterly, 4, 204-219.

Watkinson, E.J. \& Mulion, S. (1988). Playground skills of moderately mentally handicapped youngsters in integrated elementary schools. The Mental Retardation and Learning Disabilities Bulletin, 16(2), 3-13.

Wind, H.W. (1960). Sports Illustrated. May 16-23.

Wishart, J. (1996). Avoidant learning styles and cognitive development in young children. In P. Gunn and B. Stratford (Eds.), New Approaches to Down Syndrome. London: Cassell. pp. 173-205. 